\title{
Community Medicine on the Navajo Reservation
}

\author{
ROBERT L. KANE, M.D.
}

D EFINITIONS of community medicine abound. As additional medical institutions come to recognize and accept responsibility in their communities, they each must struggle to define the precise relationship. All the definitions, however, contain a common core inherent in the two components of the phrase, namely, "community" and "medicine." There must be a defined population, or community with which to work, and the work must involve the medical professions.

A frequent implication in programs of community medicine is that the diagnosis and treatment of a community may be approached in the same manner as the physician approaches his individual patients. This paper describes one conscious attempt to "practice" community medicine in an isolated rural setting.

\section{Setting}

The Shiprock Service Unit of the Indian Health Service serves the northeast corner of the vast Navajo Reservation and provides an excellent opportunity to transfer the principles of community medicine from the academic world to the reality of an isolated, culturally distinct setting. The service unit, which includes parts of three States (New Mexico, Arizona, and Utah) has relatively well-defined boundaries which encompass approximately 25,000 persons in its 5,000 square miles. The unit is the primary source of medical care for this population, providing inpatient, outpatient, emergency, dental, optometric, pharmaceutical, field, preventive, home, and environmental health services. It is also the principal third-party sponsor for much of the medical care rendered to Navajos in surrounding community hospitals and at the referral centers.

The service unit includes a

Dr. Kane, formerly service unit director, Public Health Service Indian Hospital, Shiprock, N. Mex., is assistant professor, department of community and family medicine, University of Utah College of Medicine. Tearsheet requests to Robert L. Kane, M.D., Department of Community and Family Medicine, University of Utah College of Medicine, Salt Lake City, Utah 84112. 75-bed hospital with an outpatient department that sees approximately 5,000 patients per month in the hospital clinic and four field clinics. In April 1970, the staff included 12 physicians (one of whom was the service unit director), 18 registered nurses, 15 licensed practical nurses, and 14 nursing assistants. The service unit provided complete pharmacy services through four pharmacists. There were four public health nurses, each with a driver-interpreter, under the guidance of a director of the field health nursing program.

The dental program consisted of three dentists with two dental assistants each; two of the dentists have clinics in boarding schools. An optometrist served the school population primarily. Three school nurses covered the more than 3,000 children in the Bureau of Indian Affairs boarding schools. Two sanitarians and three sanitary engineers supervised routine environmental surveillance activities and were instrumental in developing new water resources for a desert population. Two health educators worked with both the field health and hospital health staffs. 
In addition to Public Health Service facilities, there are private medical establishments in two bordering towns. With growing affluence and improved transportation, more Navajos are making use of these. But with the average family income still only about $\$ 1,200$, most Navajos must depend on the Service to provide or sponsor major medical services.

In its capacity as total medical provider, the service unit has the potential for truly comprehensive health planning. It must consider not only the persons who come to the clinic but also the total community to assess unmet health needs. It is fertile soil for the community medicine approach.

\section{Diagnosis}

Before community health planning can be done, an adequate diagnosis must be made. As with the individual patient, this diagnosis requires the use of all available information (the history) and some additional studies to collect new data (the physical examination).

\section{The History}

A vast amount of data was available to aid in the diagnosis of the multiple health problems of the Navajo community. Thanks to a good data collection system originally developed by the Navajo Area of the Indian Health Service, information was available on morbidity (both inpatient and outpatient) as well as mortality. From this information, one can calculate at least crude utilization rates for the various population groups within a service unit. The centralization of the majority of medical resources simplified the tabulation of available facilities and manpower.
Other socioeconomic data were available from community agencies and the Bureau of Indian Affairs.

A few statistics should highlight many of the problems. The Shiprock Service Unit had 300 hospital beds per 100,000 population compared with the national rate of 410 . While the national per capita health expenditure was reported by the Department of Health, Education, and Welfare at about $\$ 215$, the Shiprock Unit spent $\$ 65$. There were 92 professicnal nurses in Shiprock per 100,000 versus 331 for the nation. Similarly the local ratio of physicians was 48 per 100,000 compared with 125 nationally (1). Clearly, facilities and manpower were at a premium in this setting.

The table illustrates the incidence of many diseases common in Shiprock Service Unit as compared with the U.S. population as a whole. These data represent only minimal figures since they are calculated on the basis of first

clinic visits for that diagnosis. Those who never seek care are not reported. The incidence of tuberculosis was almost 10 times higher than the national rate. Nutritional deficiency among the Navajo has been well documented in both the popular and technical press (2).

Homicide and suicide are now both among the leading causes of death among Indians (3). Mortality data for the Navajo Area reflect the medical plight of the American Indian. The infant mortality rate for 1968 was 49.7 per 1,000 live births, versus 22.4 for the nation. The life expectancy for Navajo Indians is $\mathbf{6 3 . 2}$ years as compared with 70.5 for the general U.S. population.

Accidents are the leading cause of hospitalization. Accidents also place the greatest demand on contract medical funds. Reports from police, highway officials, and hospitals not operated by the Public Health Service confirm the menace of highway accidents in this area, particularly

\section{Incidence of selected notifiable diseases per 100,000 population, Ship- rock Service Unit, Indian Health Service, and general U.S. popula- tion}

\begin{tabular}{|c|c|c|}
\hline Disease & $\begin{array}{c}\text { Shiprock } \\
\text { Service } \\
\text { Unit }\end{array}$ & $\begin{array}{c}\text { General , } \\
\text { U.S. } \\
\text { population }\end{array}$ \\
\hline 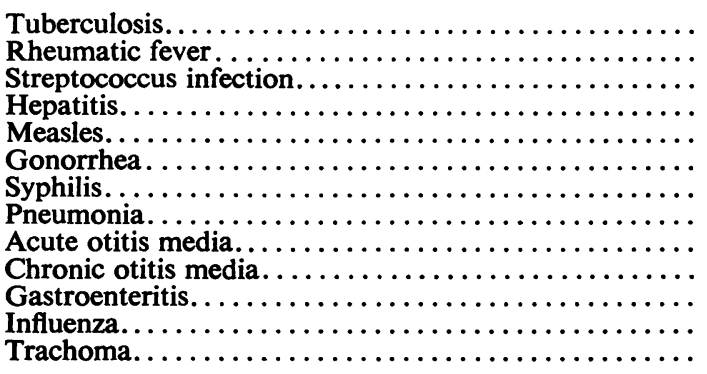 & $\begin{array}{r}200 \\
195 \\
7,500 \\
340 \\
95 \\
1,765 \\
135 \\
6,460 \\
8,965 \\
1,570 \\
12,210 \\
820 \\
1,910\end{array}$ & $\begin{array}{r}23 \\
2 \\
229 \\
21 \\
32 \\
207 \\
52\end{array}$ \\
\hline
\end{tabular}

${ }^{1}$ Not reported.

SoURCE: Justifications of Appropriations Estimates for the Committee on Appropriations, Fiscal Year 1971, Indian Health, U.S. Department of Health, Education, and Welfare as cited in "Health Problems, Health Programs, Health Program Deficiencies and Justification for Increased Fiscal Year 1971 Resources." Prepared at the request of the Navajo Tribe by the Navajo Area Indian Health Service, April 1970. 
those connected with alcohol. In one neighboring town, Navajos accounted for 2,861 arrests for drunkenness and 201 arrests for driving while intoxicated in the course of a year.

There is abundant literature describing the Navajo culture and the paramount role of medical care in the traditional system (4). Such data must comprise an important part of the community's medical "history," because they stress the fact that traditional medicine to the Navajo patient involves an intensive personal relationship with the curing person. Information about Navajo culture also emphasizes that the Navajo language (still spoken widely) is extremely difficult to translate into English.

The Shiprock region, however, has some of the characteristics of a developing nation. Although old ways are still prevalent, they are being strained by industrialization. A new electronics assembly plant has brought jobs for some 1,200 Navajos, mostly women, but it has also meant disruption of the extended family and it is a potential cause of child neglect.

\section{The Physical Examination}

Beyond the available data, other information was specifically gathered through special surveys and research projects. Studies have been carried out to assess the attitudes of consumers to medical care problems and their feelings about the care they receive at our facility. These questionnaires were administered in Navajo by Navajo interviewers in an attempt to reach consumers who had not become acculturated. Many at the service unit were surprised to find that consumers had a generally accurate concept of the major health problems.

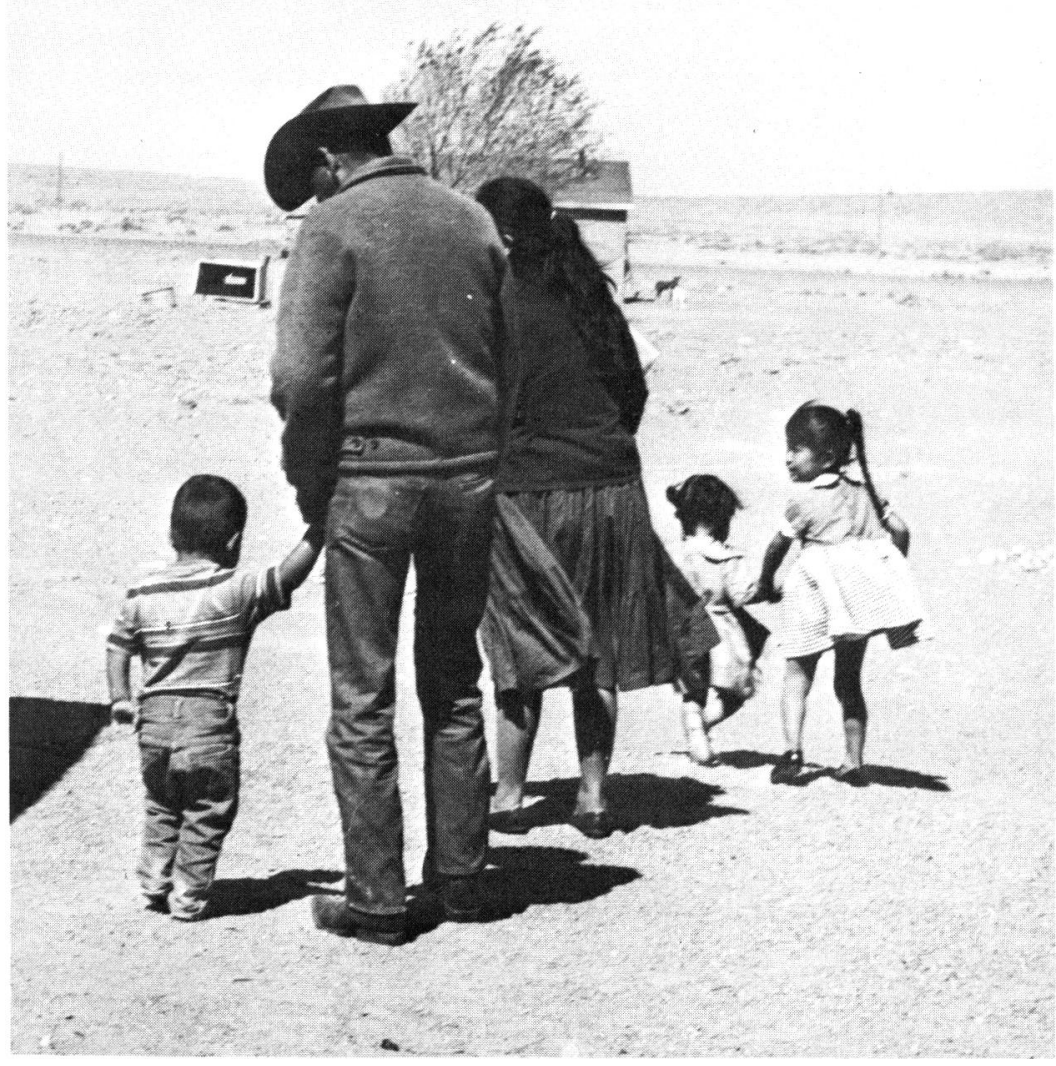

Harsh land of the Navajo Reservation surrounds this typical family

In addition, the entire staff of the service unit was surveyed to see what staff members identified as health problems and how they felt toward the population they cared for. The field health unit (comparable to a local health department in another setting) looked at itself critically, conducting a cost-self-analysis of its activities. Similarly the environmental health department sought to measure the differences in environmental living conditions between a sample of hospital patients and a control population; to their surprise, they found very few. These data, which attempt to measure the effectiveness of the present health system, were an important part of the information needed for a complete diagnosis of the health status or the community.

\section{Treatment}

A twofold approach was taken to attack the problems outlined in the preceding sections. It was necessary to aim both at improvements in direct patient services and at the same time try to collaborate with other community agencies to attack underlying community problems.

The ratio of physicians and nurses to the Indian population suggests a manpower shortage in a region where patients are culturally conditioned to expect time 
language radio program for this and other health education efforts.

Because of the high incidence of tuberculosis in the area, more than a third of the public health nurses' time is already spent in tuberculosis control. With the help of a computerized tuberculosis register, the Shiprock Service Unit is now better able to follow active cases more closely and to organize priorities of treatment and followup. A grant to support tribal community tuberculosis workers who could provide intensive followup in a program of home treatment was unfortunately not funded this year. The unit still hopes that funds to support such a decentralized program will be available soon. In an area such as the reservation with vast distances and a unique culture with its own language, a sanitorium is not the best method of tuberculosis control.

Several programs in nutrition are available. The traditional commodity food program for welfare recipients is in operation here too. Additional supplemental foods are offered to high-risk groups (regardless of welfare status) such as young children ( 1 to 5 ) or mothers. The ONEO has supported a program to provide iron-enriched formula to all premature infants during their first year of life. Plans are already made to increase nutritional counseling services, particularly in the use of commodity foods. It is also hoped that the midwife program, which will allow more time for postnatal care, will be able to reintroduce breast feeding among Navajo mothers who do not have access to refrigerators.

The Shiprock Service Unit has considered that the cultural stresses brought about by industrialization may be considered a health-related problem. Family breakup is thought to produce increased alcoholism and mental health problems, and the employment of mothers can lead to potential child neglect and malnutrition. The service unit was eager to cooperate with a private agency starting a day center for the children of working mothers and to act as physician for the nursery.

In addition, the service unit has worked closely with the major industry in the town, encouraging the plant to employ a health counselor for its 1,200 employees. This counselor would replace the traditional plant nurse, primarily providing education and guidance in areas such as family planning, maternal and child health, nutrition, and general hygiene instead of curative services.

Finally_and perhaps most important-any concept of treatment of the community has included community involvement in its health problems. Working through the newly established, tribally appointed community health representatives, the service unit has sought to establish communications with the consumers of care. These representatives have carried out a survey of what their constitutents identify as health problems. At the same time they have begun to explain what services and what limitations define the Public Health Service's ability to respond to these demands.

The concept of local health boards has been introduced across the Navajo Reservation. We at the service unit level saw these boards as an essential step in establishing an effective relationship with the community. The unit has advocated the formation of such a body at every opportunity, at chapter meetings, talks, school board meetings, and informal discussions. It has already begun to provide the community with the necessary information about workloads, inadequacies of personnel and facilities, and other comparative statistics in a fact sheet intended to help the boards appreciate the constraints under which operations are conducted.

The question of a health board raises issues not unique to the Navajo but which may have implications for all federally financed medical care. The appropriate role of consumer representatives in health care planning is the subject of a long debate. In the context of a system which is dependent on Federal lump-sum financing, the need for a consumer advocate becomes dual. $\mathrm{He}$ must not only represent the consumer to the providers of care, but he must also be prepared to justify the providers' needs for funds. This aspect has particular relevance to the Navajo and must influence the feelings of both providers and consumers toward the need for a health board.

\section{Research}

The research potential of a setting such as the service unit must be used to the best advantage of the community. As a means of bringing in new insights and energies into old problems, research offers an outlet to staff who have labored under the frustrations of a limited budget. The opportunity to conceptualize a real but amorphous problem may be the most significant step toward solving it.

I have mentioned the consumer study which has brought new insights into health planning. 
The attitudinal study of the unit's staff revealed the need to support inservice programs and additional effort. The environmental health survey which compared the environmental conditions of the homes of a series of hospital patients with those of a control group has provided a means for integrating the sanitarians and sanitary engineers with the personnel in the curative system. Abstracts of the survey findings were sent to the physician of each patient studied as an aid for disposition planning. Interest among the field health staff led to plans for possible comprehensive home evaluations with a multidisciplinary approach.

Students provide another source of stimulation for an isolated area, and we encouraged students from a variety of professions. These students brought with them enthusiasm and current information from the educational centers. Their questions often illuminated dark corners otherwise hurried past, and their energies made possible unbudgeted research projects. Often they provide the basis for affiliations with medical schools which may lead to formal and informal exchanges of personnel as well as ideas.

Research, performed by either staff or students, must never be undertaken in a setting such as this for its own sake. Wasting time and personnel on abstract questions would soon lead to a lowering of morale. But research which is clearly related to program planning can easily capture the imagination of the staff to the extent that persons often are eager to devote their free time to such projects.

An example of research contributing to program change is the attitudinal study of service unit personnel. This research so pointed up the deficiencies in communication and understanding between various departments that it offered guidelines for inservice training. Moreover, it led to the decision to close the outpatient clinics for one-half day a week in order to enable communication among the departments and disciplines within the service unit.

A successful study in terms of leading to a new action, however simple, is likely to set the stage for more research. A physician may decide to develop a new form on a trial basis-another department may decide to examine its activities meticulously. In an environment which can readily become stagnant with discouragement because of limitations of funds, an inquiring spirit is an important first step to creative new actions. In this process the service unit has found that simple, short-term, program-related research projects have led to other studies of the same nature.

\section{Discussion}

It would seem that the concept of community medicine can be successfully transplanted from the academic hothouse to the desert soil of everyday practice. I have attempted to regard the community as a patient and to treat all aspects of this patient's problem at once. In so doing the traditional troika of medicinepatient care, teaching, and research-has added a fourth horse-community involvement. These four interrelated elements required balancing in our efforts to look at the health problems of Shiprock in an integrated way.

I wish to emphasize that this discussion is presented as an example of an approach-not as a set of specific recommendations for an area comparable to the Shiprock Service Unit. Indeed not all the methods employed were equally successful, and some clearly were unworkable. But treating a community is a dynamic process calling for continuing trial and rediagnosis. It is important to begin on as many fronts as possible-one could delay action interminably waiting for the right place to start. And fear of failure should be limited to the clinician's usual caution in considering possible complications and risks. In transferring the philosophy of community medicine into practice, we at the Shiprock Service Unit have felt that we must plunge ahead with our "treatments" and observe the results. Our service unit could have avoided mistakes by making no new decisions, but in community medicine terms this would have been the greatest mistake of all. To extend our metaphor, it would be equivalent to observing the patient during the course of his illness through a one-way screen without any attempt at interaction.

\section{REFERENCES}

(1) Fein, R.: The doctor shortage. The Brookings Institution, Washington, D.C., 1967.

(2) Van Duzen, J., Carter, J. P., Secondi, J., and Federspiel, C.: Protein and calorie malnutrition among preschool Navajo Indian children. Am J Clin Nutr 22: 1362-1370, October 1969.

(3) Ogden, M., Spector, M. I., and Hill, C. A., Jr.: Suicides and homicides among Indians. Public Health Rep. 85: 75-80, January 1970.

(4) Kluckhohn, C., and Leighton, D.: The Navajo (revised edition). Doubleday \& Co., Inc., Garden City, N.Y., 1962.

(5) Weed, L. L.: Medical records, medical education, and patient care. The Press of Case Western Reserve University, Cleveland, Ohio, 1969. 